\title{
Effect of head movement on the localization of sounds in the equatorial plane
}

IRWIN POLLACK AND MITCHEL ROSE

MENTAL HEALTH RESEARCH INSTITUTE, UNIVERSITY OF MICHIGAN

Five experiments examined the effect of head movement on the localization of sound sources in the equatorial plane. Under most conditions, head movement produces poorer localization for sound sources in the equatorial plane. Only one condition demonstrated an improvement in localization with head movement. The sound source was located toward the side of the head and the source duration was long enough to permit reorientation of the position of the head with respect to the sound source.

Phenomenologists and philosophers have long been concerned with the apparent stability of our perceived environment when we move. For example, sound sources appear fixed despite changes in our head and body position. We presumably infer the location of sound sources during movement on the basis of kinesthetic cues from the neck and other muscles and from the apparent location of sounds at the ears. In fact, for some sensory theorists, movement through the environment is a necessary condition for building up adequate spatial relationships (Held, 1955).

Head movement might, in addition, be expected to improve the localization of sound sources by introducing relative time-intensity differences to the two ears. The movement of the head in selection among competing sound sources has, in fact, been given the accolade of scientific jargon as the "cocktail party effect." Head movement is presumably effective at cocktail parties because it presents different orientations of the ears to the desired source and to the competing sources. Despite the sheer volume of evidence provided by the cocktail party, head movement may be primarily effective in localization only when listening against competing sound sources. Head movement may actually play little role in localization without competing sound sources. This speculation cannot be entirely correct. Wallach (1940) demonstrated that the ambiguity of localization typically observed for sound sources in the sagittal plane (the plane of a saw splitting the nose) improves with head movement. Such a result is reasonable because time and intensity differences at the two ears are zero for the stationary head for sources in the sagittal plane. Moreover, as Wallach $(1939,1940)$ has shown, the relative time-intensive differences associated with head movement change with azimuth position, being zero for overhead sound sources and maximal for sound sources at the intersection of the sagittal plane and the equatorial plane (the plane of a saw splitting the waist).

Wallach also reported that head movement is effec- tive in localization within the equatorial plane, but no control measures with the non-moving head were presented. We felt the problem was sufficiently important to reopen the analysis of the role of head movements in the localization of sound sources in other than the sagittal plane.

The entire question of the effect of head movement upon sound localization may be recast by analogy to the problem of visual search. The visual acuity of the central portion of the retina, the fovea, is considerably sharper than that of peripheral portions of the retina. In examining an object of fine detail, we repeatedly sweep the central foveal region across the object. Likewise, in sound localization, the acuity for displacement of a sound source in the nose-ahead position is somewhat sharper than for sound sources at the side of the head. We therefore might expect head movement to improve accuracy of localization of sustained sounds in the equatorial plane by reorienting the ears into more acute listening positions.

\section{METHOO}

Five experiments were conducted. In each study, 19 small loudspeakers (Quam 549, 2-1/2 in. square) were arranged at ear level along a semicircular arc 5-6 ft from the center of the S's head. Speakers were spaced at equal intervals. The rightmost loudspeaker was labelled "1"; the center speaker was labelled "10"; and the leftmost speaker was labelled "19." S's task was to identify the activated loudspeaker. Loudspeakers were interehanged so that acoustical quality was not differential. Testing sessions lasted about $50 \mathrm{~min}$. Ss were undergraduates with apparently normal hearing in both ears. Ss were tested individually. Series 1,2 and 3 employed different groups of three listeners. Series 4 used two of the listeners of Series 3. Series 5 employed two listeners.

Series 1 was conducted in a medium size anechoic chamber (Peterson et al, 1967). The chamber is equipped with fiberglass wedges on all sides with a grilled floor. It is estimated that the cutoff frequency of the room was about $80 \mathrm{~Hz}$. Loudspeakers were spaced 9.6 deg apart.

$\mathrm{S}$ was tested with his head oriented straight-ahead and with his body oriented in one of three positions: A, straight-ahead; B, facing $90 \mathrm{deg}$ to the right (i.e., with the chin over the left shoulder); or C, facing $90 \mathrm{deg}$ to the left. The order of testing was ABBACC. S presented the sound by means of a push button. The signal was a click of about $15 \mathrm{msec}$ duration produced by 
a condenser discharge across the speaker. Its peak level was about $86 \mathrm{~dB}$ SPL. The mean number of observations per $S$ for each orientation was 407 .

Under conditions of a moving head, two directions of movement, sweeping from left to right and vice versa, combined with two rates of movement, 120 or $40 \mathrm{deg} / \mathrm{sec}$, were employed. The loudspeaker was activated by the commutator attached to $S$ through a head band. The click could be emitted at any one of nine selected head locations (corresponding to nose orientations to speaker locations $2,4, \ldots$ 18). All possible head locations by loudspeaker combinations were employed within the limits imposed in the non-moving head tests. Specifically, with the moving head triggering when $\mathbf{S}$ faced speaker 10 , loudspeakers 1 through 19 were employed. With the moving head triggering when $S$ faced loudspeaker 2, only loudspeakers 1 through 11 were employed. The average number of observations under the moving head conditions was 428 per $S$.

Series 2, 3 and 4, were conducted in a $10 \mathrm{ft}$ by $11 \mathrm{ft}$ recording studio with fiberglass matted walls and carpeted floors. The room, smaller than the anechoic chamber, was not anechoic, but was reasonably free of echoes. Loudspeakers were spaced 3.2 deg apart.

The four conditions with a moving head were similar to those in Series 1. A relay-light timing system mounted above the speakers was employed to pace the rate of head movement. $S$ was instructed to follow the lights with his head. In the moving head conditions, $S$ was instructed not to reverse his direction of movement sharply, in order to avoid double clicks. Because of the time uncertainty associated with the moving head condition, E presented the click in the nonmoving head tests. In a given test session, only one of the five experimental conditions was examined. The order of testing across sessions was scrambled over Ss. The mean number of observations per condition was 287 for each $\mathrm{S}$.

Series 3, 4 and 5 employed unconstrained head movements. $S$ was instructed to move his head as if "searching for an auditory target" within the range of the speakers. Ss began head movements on a verbal signal from $\mathrm{E}$, who presented a sound randomly within the next $6 \mathrm{sec}$. Two sounds were employed: the click discharge and a $1 \mathrm{sec}$ white noise. In each session, only one type of sound was presented. Data were collected

\section{LOUDSPEAKER POSITION IN DEGREES}

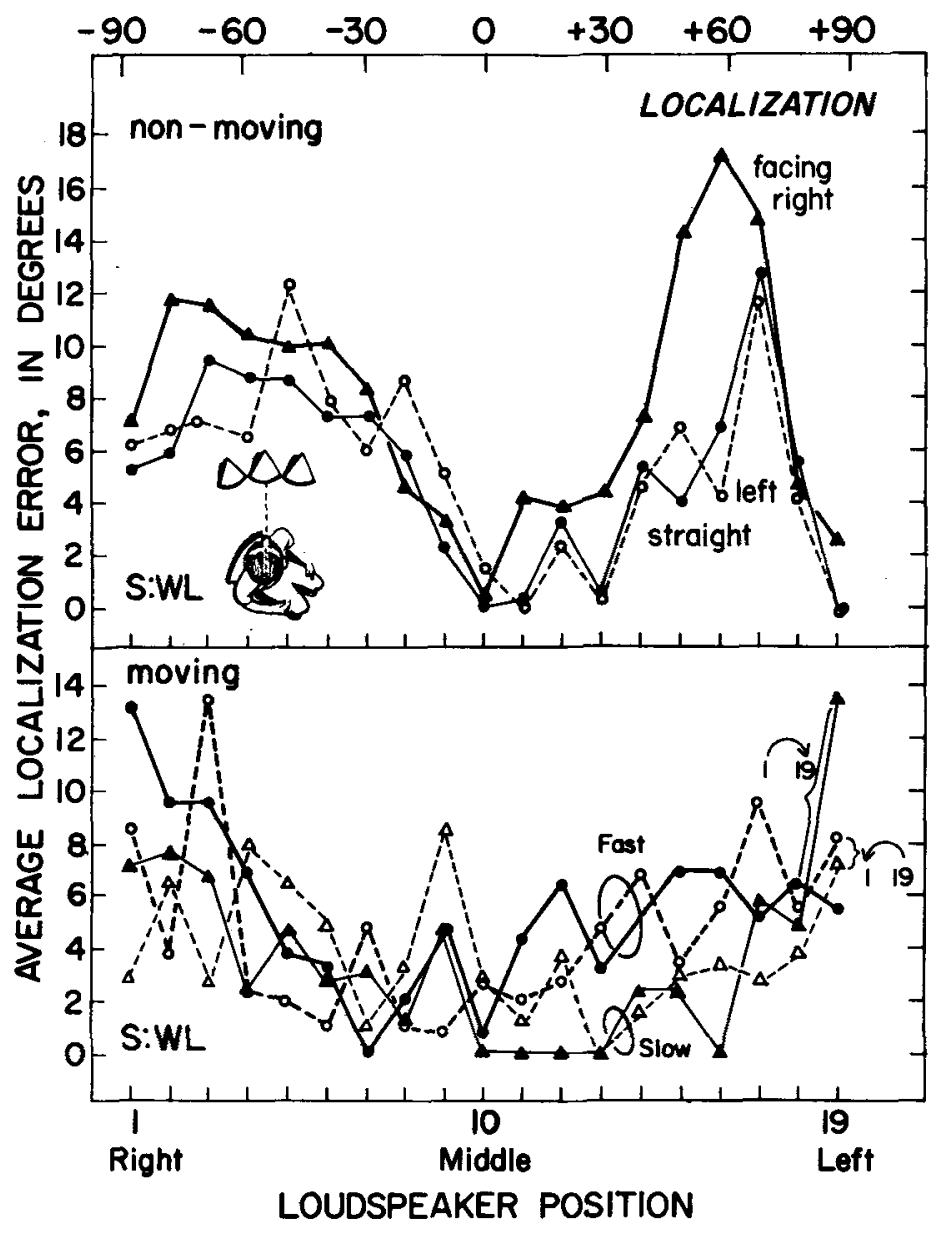

Fig. 1. Average localization error in degrees as a function of loudspeaker position. Series 1 , wide spacing. Top section: non-moving head with shoulders facing straight, right or left. Bottom section: moving head. Data for a single $S$. 
Table 1. Average Localization Error, in Degrees, for Series 1

\begin{tabular}{|c|c|c|c|c|c|}
\hline \multicolumn{3}{|c|}{ A. Stationary } & \multicolumn{3}{|c|}{ Orientation of Body } \\
\hline & & & Aheod & To Left & To Right \\
\hline S: & $\begin{array}{l}\text { W.L. } \\
\text { A.K. } \\
\text { G.B. } \\
\text { Average }\end{array}$ & & $\begin{array}{l}5.3 \\
6.1 \\
6.0 \\
5.8\end{array}$ & $\begin{array}{l}5.4 \\
5.7 \\
6.1 \\
5.7\end{array}$ & $\begin{array}{l}8.0 \\
7.0 \\
8.3 \\
7.8\end{array}$ \\
\hline & & Fast & Fast & Slow & Slow \\
\hline & $\begin{array}{l}\text { Moving } \\
\text { Head }\end{array}$ & $1 \rightarrow 19$ & I9 & $1 \rightarrow 19$ & $19 \rightarrow 1$ \\
\hline S: & W.L. & 5.5 & 4.7 & 3.6 & .3 .8 \\
\hline
\end{tabular}

for the nonmoving head in an ABBA sequence with head movement. The mean number of observations per condition was 380 for each S.

Series 4 employed a white noise signal which varied in duration between .03 and $3.0 \mathrm{sec}$. Nonmoving head tests were also run with a scrambled order of presentation among the five stimulus durations and two head movements. The signals were adjusted to be subjectively equal in loudness at all stimulus durations to a $3 \mathrm{sec}$ burst at $58 \mathrm{~dB}$ SPL. E presented the sound within a $6 \mathrm{sec}$ interval after a preparatory signal and $S$ responded when the sound had ceased. The mean number of observations per experimental condition was 152 for each $\mathrm{S}$.

Series 5 was conducted in a $6 \mathrm{ft} \times 6 \mathrm{ft}$ acoustical chamber (Industrial Acoustics Co.). The room, with a carpeted floor, was reasonably free of echoes. Loudspeakers were mounted 3 deg apart. The signal was a white noise, $3 \mathrm{sec}$ in duration, at a sound level of $54 \mathrm{~dB}$ SPL.

Two conditions of head movement, moving and nonmoving, were coupled with five starting positions: $0 \mathrm{deg}$, facing speaker 10,45 deg to the left and to the right, and 90 deg left and right. In the moving conditions, $S$ initiated movement only after the signal had begun. $S$ was also permitted to move his body on a swivel chair. The mean number of observations per experimental condition was 76 per $\mathrm{S}$.

\section{Series 1}

\section{RESULTS AND DISCUSSION}

The first portion of Series 1 attempted to examine the effect of extreme neck position on the localization of a brief signal for the nonmoving head. Sensorytonic theory (Werner \& Wapner, 1952) suggests that extreme distortions of neck position might be expected to yield poorer accuracy of localization.

Figure 1 presents the mean absolute deviation (average error) between the presented target and the localized target for one $S$ as a function of the orientation of the presented target. The upper portion presents results for the nonmoving head conditions. Most accurate localization is obtained for the straight-ahead region (except for the extreme positions where errors of only one direction could be obtained). Accuracy of localization is largely unaffected by extreme differences in body position (to the left), although accuracy of localization appears to suffer with body position to the right. The results for the other two Ss confirm those in the upper portion of Fig. 1. The general findings are verified by an analysis of variance which shows a significant effect of loudspeaker position $(F=5.99$, $p<.01)$. The upper portion of Table 1 presents a summary of the experimental results, averaged across speaker positions for each $\mathrm{S}$.

The second portion of Series 1 attempted to determine the role of head movement for click localization. The bottom section of Fig. 1 presents results for the same listener under four conditions of head movement. The designation of the presented loudspeaker position is with reference to the orientation of the nose. Separate analyses of variance examined the conditions of nonmovement and the two speeds of movement. No significant condition effect was found with either of the head movement rates paired against non-movement. Rate of head movement, however, was significant $(p<.05)$. Loudspeaker position was significant $(p<.05)$ but only in analyses including slow head movement. The findings are qualified by the fact that tests with head movement were carried out after tests without head movement. Also, any slippage in the commutator system would result in a smoothing across loudspeaker position. The lower portion of Table 1 presents a summary of the experimental results, averaged over speaker position. Since the average error in localization was about one half of the separation between successive speakers, subsequent series employed a narrower spacing among loudspeakers.

\section{Series 2}

Series 2 was concerned with the role of constrained head movements in the localization of a brief click.

The results of one $S$ for Series 2 are presented in Fig. 2. The four conditions of programmed head movement are largely nondifferentiated and all are clearly poorer when compared with a nonmoving head position. We also note, that for the reduced range of loudspeaker positions, the effect of loudspeaker position is small for both nonmoving and moving head. The results for the two other Ss confirm the findings of Fig. 2.

The results for all Ss are summarized in Table 2, averaged over loudspeaker position. Analysis of variance confirms the general findings: significant effects of each rate of movement compared with nonmoving head $(p<.01)$.

The head movements which were employed in Series 1 and 2 are not the type that our listeners normally use to localize sounds in the natural environment. Rarely does one confine his neck movements to a single plane without forward-aft movement. Attention to the pacing light, coupled with the requirements of 


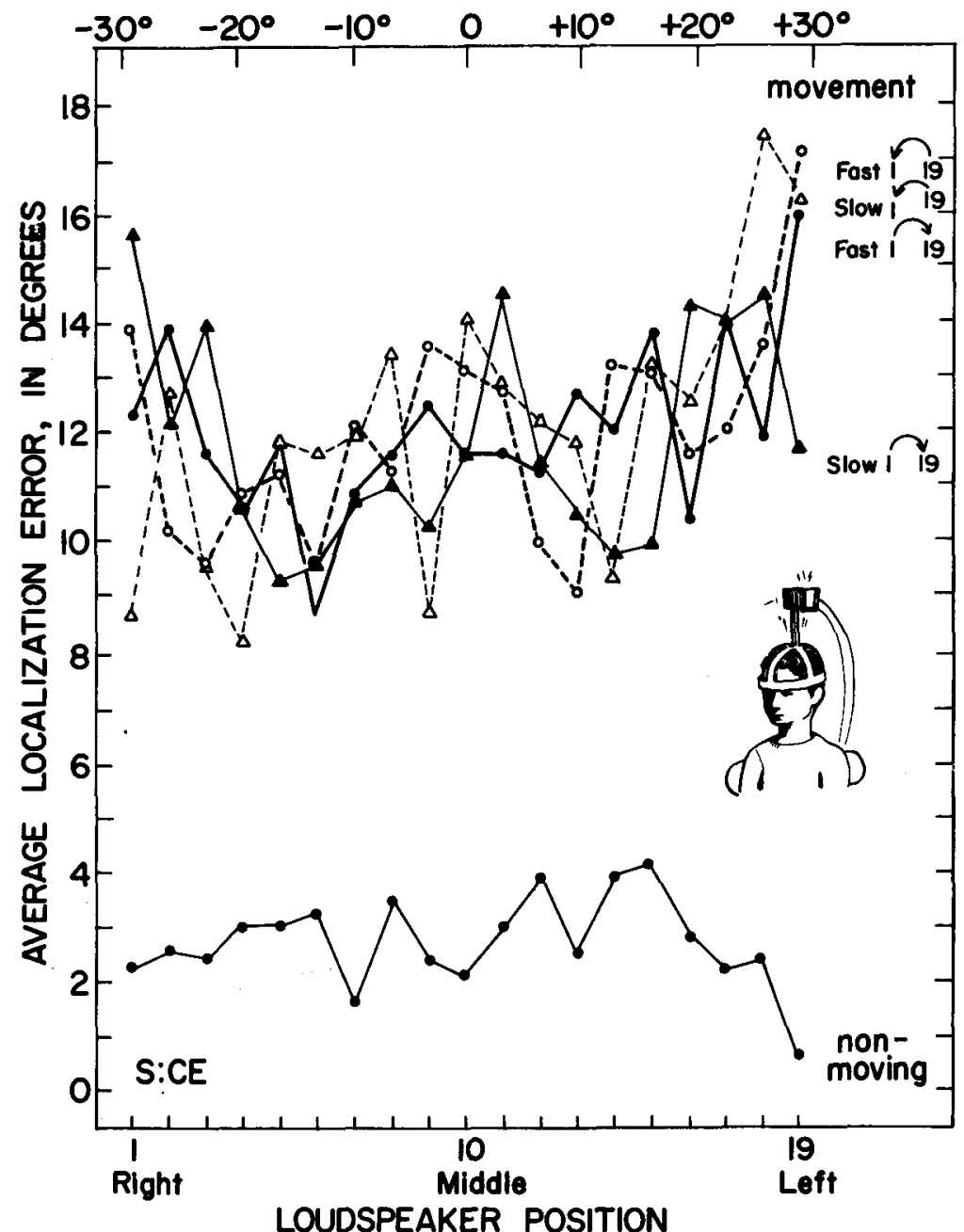

Fig. 2. Average localization error in degrees as a function of loudspeaker position. Series 2, narrow spacing. Data for a single $S$. single plane movement, may have been sufficient to impair localization. Subsequent tests, therefore, employed free head movements.

\section{Series 3}

Series 1 and 2 did not permit the reorientation of the ears to a more acute listening position because of the use of a short click. Their main point is that, for brief stimuli, constrained head movement may result in a decrement in localization. Series 3 compared the role of head movement for sound sources of different

Table 2. Average Localization Error, in Degrees, for Series 2

\begin{tabular}{ccrccc} 
& $\begin{array}{c}\text { Fast } \\
1 \rightarrow 19\end{array}$ & $\begin{array}{c}\text { Fast } \\
19 \rightarrow 1\end{array}$ & $\begin{array}{c}\text { Slow } \\
1 \rightarrow 19\end{array}$ & $\begin{array}{c}\text { Slow } \\
19 \rightarrow 1\end{array}$ & $\begin{array}{c}\text { Non- } \\
\text { move. }\end{array}$ \\
$\begin{array}{ccrcc}\text { Subject } \\
\text { RL }\end{array}$ & 10.5 & 9.8 & 9.8 & 10.2 & 3.4 \\
CE & 11.9 & 11.9 & 11.7 & 12.0 & 2.7 \\
DD & 10.9 & 9.6 & 10.9 & 10.1 & 3.2 \\
Average & 11.1 & 10.4 & 10.7 & 10.7 & 3.1 \\
\hline
\end{tabular}

durations. $S$ was permitted to move his head freely to "search for the target."

The results for one $S$, who demonstrated the sharpest separation among the conditions of Series 3, are presented in Fig. 3. Since the location of S's head position at the moment of the click was not recorded, the abscissa refers to the loudspeaker spatial position for all conditions. Several points are noted in Fig. 3: a strong effect of loudspeaker position is observed for the brief click and nonmoving head position is observed for the brief click and nonmoving head position (this strong effect is not found for the other Ss), but the effect is weak for the other conditions; accuracy of localization is better for the longer duration signal.

Table 3 summarizes the results of Series 3 , averaged over loudspeaker positions for each of three Ss. Analysis of variance confirms the strong effect of duration $(p<.01)$ and the significant effect of head movement $(p<.01)$. 


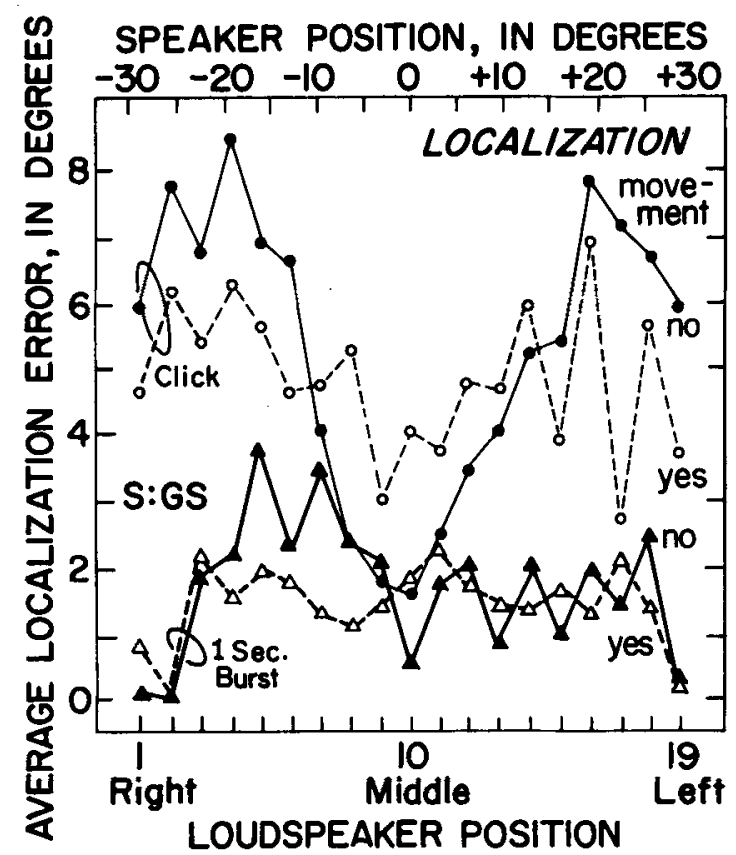

Fig. 3. Average localization error in degrees as a function of loudspeaker position. Series 3 , narrow spacing. Data for a single $S$.

\section{Series 4}

Series 4 attempted to determine whether the superiority of the longer signal in Series 3 was specifically related to its duration. The click and nolse of Series 3 also differed with respect to frequency composition.

Figure 4 presents the average error for each of two Ss for each of the durations examined. An analysis in terms of loudspeaker position confirms the results of Fig. 3. Only small position effects are obtained for long duration signals, but large effects may be obtained with short duration signals.

For both Ss, accuracy of localization with stationary head is superior to moving head for the four shortest stimulus durations. The small improvement in accuracy with the $3.0 \mathrm{sec}$ duration with head movement may have been due to S's reported boredom of holding his head stationary for $3 \mathrm{sec}$ or to providing ample time for reorientation of the moving head with respect to the source. Analysis of variance confirms the mean superiority of nonmoving head position $(p<.01)$ and of duration $(p<.01)$ and confirms the interaction of head movement with duration $(p<.01)$.

Table 3. Average Localization Error, in Degrees, for Series 3

\begin{tabular}{|c|c|c|c|c|}
\hline & & & 1.se & Irst \\
\hline & $\begin{array}{l}\text { Non- } \\
\text { move. }\end{array}$ & $\begin{array}{l}\text { Move- } \\
\text { ment }\end{array}$ & $\begin{array}{l}\text { Non- } \\
\text { move. }\end{array}$ & $\begin{array}{l}\text { Move- } \\
\text { ment }\end{array}$ \\
\hline Subject & & & & \\
\hline $\mathrm{KS}$ & 3.1 & 3.4 & 3.1 & 2.3 \\
\hline GS & 5.2 & 4.8 & 1.9 & 1.4 \\
\hline$V L$ & 4.8 & 4.1 & 3.3 & 3.0 \\
\hline Average & 4.4 & 4.1 & 2.8 & 2.2 \\
\hline
\end{tabular}

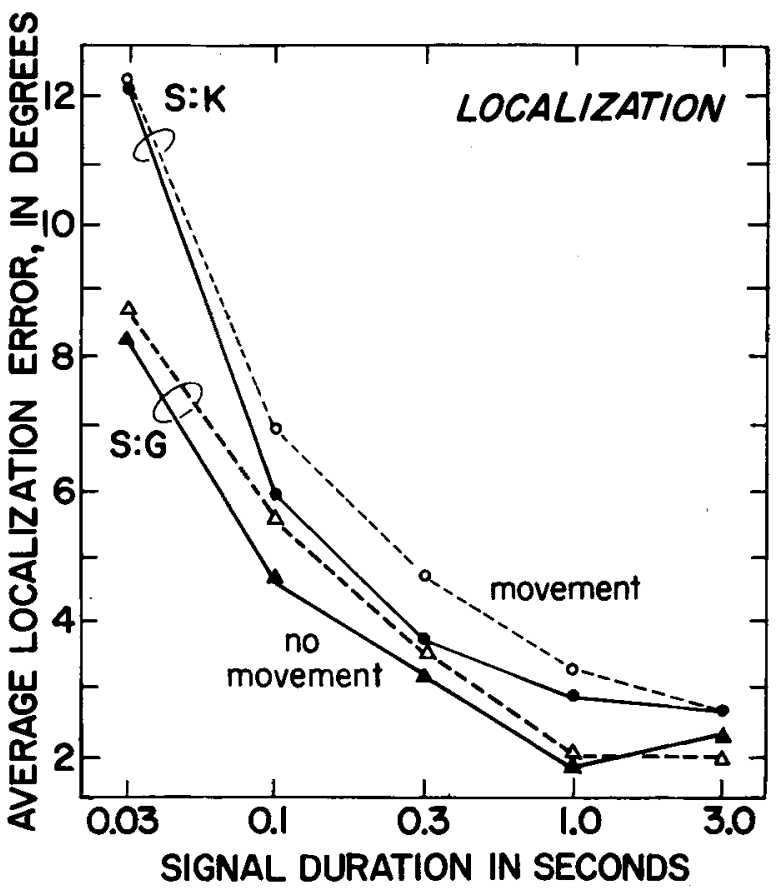

Fig. 4. Average localization error in degrees as a function of signal duration in seconds. Series 4; narrow spacing. Data for each of 2 Ss.

Thus, even with sound durations sufficiently long to permit head reorientation to the source, there is no clear-cut gain in localization with head movement.

\section{Series 5}

Series 5 attempted to stack the conditions in favor of obtaining a positive effect of head movement upon localization. We accomplished this by degrading the accuracy of localization for the nonmovement conditions through the use of listening positions on one side of the head, and by providing the opportunity for gross reorientation under head movement through the use of a long sustained signal.

The results for two Ss for Series 5 are presented in Fig. 5 as a function of the listener's initial offset relative to the center of the speaker array. As the offset is increased, the average localization error increases markedly for the nonmoving head, and is relatively independent of offset for the moving head.

We finally succeeded in demonstrating what should have been obvious from common experience: there exist a set of conditions for the localization of sounds in the non-sagittal plane where there is a clear advantage for head movement. The necessary conditions appear to be: (1) sustained sounds which permit gross reorientation of the ears to the source, and (2) sound sources outside of the central "cone of maximal sensitivity." As the more interesting feature, however, the results suggest that small adjustive head movements do not substantially improve the accuracy of localization of a sound source in the non-sagittal plane when heard against a quiet background. 


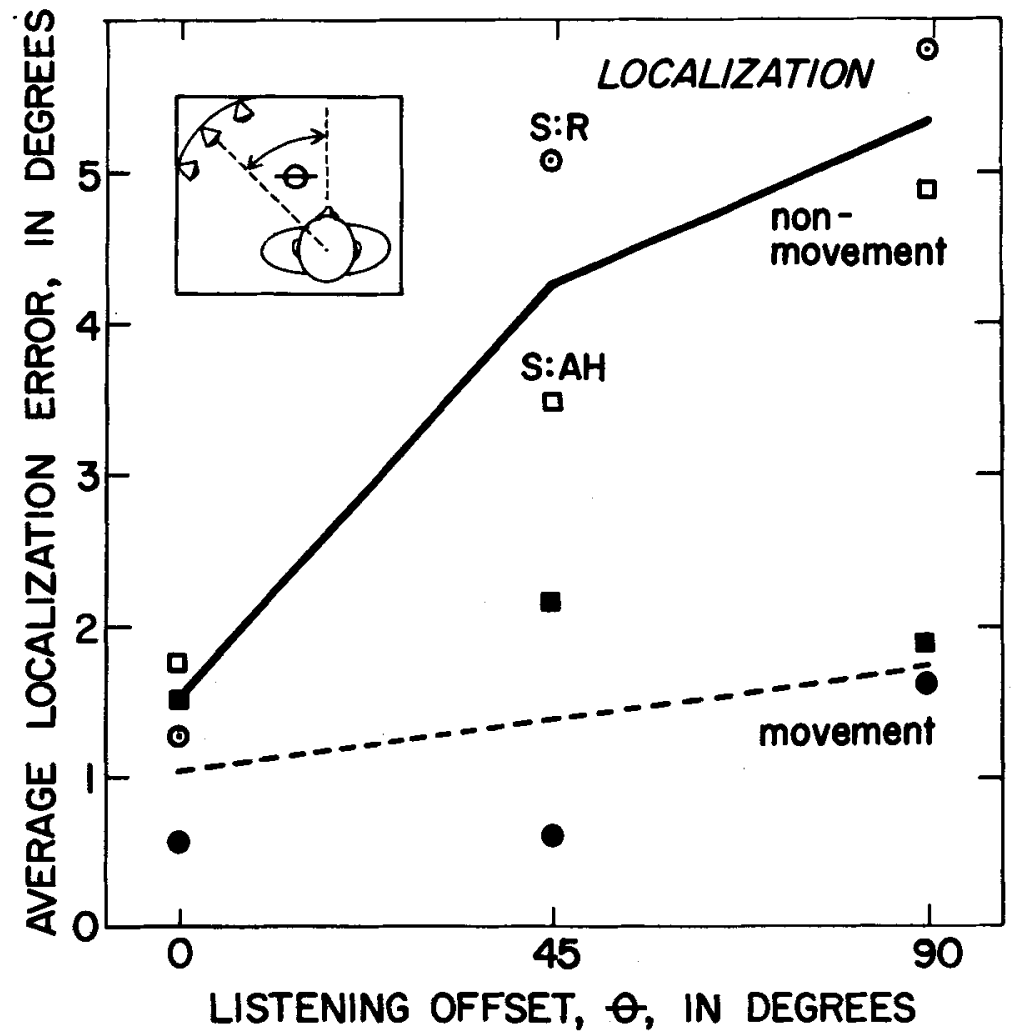

Fig. 5. Average localization error in degrees as a function of listening angle. Series 5; narrow spacing; 3-sec noise burst. Data for each of 2 Ss.

\section{References}

Held, R. Shifts in binaural localization after prolonged exposures to atypical combinations of stimuli. Amer. J. Psychol., 1955, $68,526-548$.

Peterson, G. E., Hellwarth, G. A., \& Dunn, H. K. An anechoic chamber with blanket-wedge construction. J. Audio Engineering Society, 1967, 15, 67-72.

Wallach, H. On sound localization. J. Acoust. Soc. Amer., 1939, $10,270-274$.

Wallach, H. The role of head movements and vestibular and visual cues in sound localization. J. exp. Psychol., 1940, 27, 339-368. Wemer, H., \& Wapner, S. Toward a general theory of perception. Psychol. Rev., 1952, 59, 324-338.

\section{Note}

1. This research was supported in part by National Sciences Foundation Grant GB2894.

(Accepted for publication July 31, 1967.) 